\title{
PUBLICACIONES CON EDITORES INVITADOS: FORMA DE CONSTRUIR CIENCIA EN RED
}

Publications with guest editors: way to build science on the net

Wileidys Artigas*

https://orcid.org/0000-0001-6169-5297

Como citar: Artigas, Wileidys. (2021). Publicaciones con editores invitados: forma de construir ciencia en red. Telos: revista de Estudios Interdisciplinarios en Ciencias Sociales, 23 (3), Venezuela. (Pp. 510-512).

DOI: www.doi.org/10.36390/telos233.01

Como editores buscamos continuamente la forma de interrelacionarnos con nuestros pares para el desarrollo de redes de colaboración e investigación que beneficien nuestro desarrollo académico, sin embargo, es conocido que dado el alto volumen de trabajo que enfrentamos con la revisión de documentos científicos, nuestro propio trabajo académico y de investigación, muchas veces se hace extremadamente difícil, y en muchos casos atenta contra el desarrollo de proyectos mayores, pues se termina en aislamiento.

En este sentido, Telos: revista de estudios interdisciplinarios en Ciencias Sociales se encuentra actualmente realizando un gran esfuerzo para estrechar procesos de colaboración con académicos destacados que deseen participar y aprender sobre la edición de revistas científicas, en números pasados ya habíamos tenido la colaboración del Dr. Robinson Salazar, gran amigo de la casa y del Dr. Lisandro Alvarado, quien representa una red de investigación.

En este caso, nos enorgullecemos de presentar una sección de este número con el Dr. Oscar Montiel Méndez, destacado académico de la Universidad Autónoma de Ciudad Juárez (UACJ), México, por tanto, observaran en este número algunos artículos especialmente dedicados a la idea de construir teoría necesaria para hablar de una "Escuela Latinoamericana de Negocios", muchos de ellos en idioma ingles, un gran salto también en nuestros procesos editoriales.

\footnotetext{
* Editora de la Revista. Doctora en Ciencias Sociales, mención Gerencia. Profesora e investigadora de la Facultad de Ciencias Económicas y Sociales de la Universidad del Zulia. Asesora en el área de Revistas Científicas de la Universidade Óscar Ribas de Angola. Correo electrónico: wileidys@hotmail.com; wileidys.artigas@urbe.edu.ve
} 
En este caso, presentaré un resumen de los ocho artículos que han llevado su proceso normal de edición y luego haré una breve referencia sobre los artículos que fueron editados por el Dr. Montiel, ya que más adelante el tendrá su propio espacio para hacer la debida introducción:

- La programación neurolingüística en los directivos de las organizaciones educativas peruanas en tiempos de pandemia, de Jorge Romero Chacín, Rosario Romero Parra y Luis Barboza Arenas.

- La crítica al marxismo en el pensamiento de Carlos Rangel de Leonardo Osorio.

- Narrativas emergentes sobre la construcción de paz indígena en Colombia: la resistencia sentipensante del pueblo Nasa Wes'x-Tolima de Eduardo Sandoval Forero y José Javier Capera Figueroa.

- ¿Citan las mujeres investigadoras más a las otras mujeres que a los hombres? De Nicoleta-Roxana Dinu.

- Universidad Autónoma Venezolana: expectativas de las autoridades rectorales de Norma M. Caira Tovar y José Sánchez Morles.

- Typical mistakes in the writing speech of bilingual students de Irina Aleksandrovna Dinevich (primera colaboración desde Rusia).

- Rendimiento académico de estudiantes en educación superior: predicciones de factores influyentes a partir de árboles de decisión de Brenda Díaz-Landa, Rosana Meleán-Romero y William Marín-Rodriguez.

- Elementos determinantes de la dinámica gerencial de enfermería para el cuidado solidario en un hospital de ESSALUD, Perú, de Patricia Bolaños Grau.

Como se puede observar, nuestros artículos son diversos, desde educación, filosofía, violencia, información y gerencia, destacando nuestro carácter interdisciplinario centrado en ciencias sociales.

Posteriormente se visualizan los artículos gestionados por el editor invitado, destacando su propia presentación que denominó: Latin America School of Business Taught (LASBT): An initial reflexión, como se señalan a continuación:

- Driving and restraining forces of female Latin American entrepreneurship de Anel Flores-Novelo, Ana Bojórquez Carrillo y Gabriela Carla Cuadrado Barreto.

- Open innovation from the university to local enterprises: conditions, complexities and challenges de Lorena Álvarez-Castañón y Rafael Palacios-Bustamante.

- East Asian studies in Latin America and its potential contributions for an improved inter-regional business understanding de Yunuen Mandujano-Salazar.

- Familia y empresas un análisis desde la antropología social de Maria Santos Corral y Rebeca de Gortari Rabiela. 
- Financiamiento para investigaciones en Innovación Social de la Academia Latinoamericana: Retos y desafíos de Mario Enrique Vargas Sáenz y Cristina Escudero Pulgarín.

Como puede observarse, de esta manera la revista amplia el espectro de sus colaboraciones, puede llegar a públicos más específicos, puede tratar temas particulares con la ayuda de expertos, entre otros elementos que en suma benefician el proceso editorial. Nuestra gratitud al Dr. Montiel por el proceso llevado a cabo que fue iniciado en febrero de 2021 y que culmina con éxito después de siete meses de trabajo continuo. Recomendamos ampliamente a las revistas y sus comités editoriales desarrollar los procedimientos para este tipo de colaboración pues generan grandes beneficios en el desarrollo de la revista.

Por otro lado, nuestros mejores deseos para el 2022, puesto que la próxima entrega de la revista vendrá para inicios de año, ya a esta fecha hemos adaptado muchos de los procesos a las nuevas realidades, pero seguramente seguiremos cambiando, pues se ha hecho la constante luego de la pandemia. 